Article

\title{
The Role of Spontaneous Digital Play during Young Patients' Cancer Treatment
}

\author{
Teresa de la Hera * and Camila Sarria Sanz \\ Department of Media and Communication, Erasmus University Rotterdam, 3000 DR Rotterdam, The Netherlands; \\ E-Mails: delahera@eshcc.eur.nl (T.d.I.H), camila@quanticaeducation.com (C.S.S.) \\ * Corresponding author
}

Submitted: 8 May 2020 | Accepted: 17 June 2020 | Published: 6 January 2021

\begin{abstract}
In Europe alone, more than 120,000 children and 150,000 adolescents are diagnosed with cancer every year. Thanks to treatment innovations the survival rates of young patients' cancer increase substantially every year, but improved prognoses are in many cases linked to longer treatments. To cope with the social, emotional, and developmental challenges associated with cancer, play and playful activities are widely recognized as fundamental for adolescents and children. This article presents the results of an exploratory study conducted to better understand the role of free digital play for young cancer patients (0-17 years). Methodology: 15 semi-structured qualitative interviews were conducted, divided into two groups. The first group consisted of four experts and the second group consisted of 11 parents of young cancer patients. Conversations with the participants revolved around children's use of digital platforms during cancer treatment, emphasizing their motivations to play digitally, methods and patterns of use, perceived benefits, and impact on children's social interactions, identity development, and personal narrative. The results show that digital play becomes a valuable activity for young cancer patients during three phases of the treatment: (1) inpatient care; (2) outpatient care; and (3) remission. We also identified three types of digital play patients engage with: (1) playing with digital games; (2) playfully interacting with digital technologies; and (3) the overlap between digital and non-digital play. Finally, the results also show that digital play has an impact on at least three aspects of young patients' lives: (1) social interactions; (2) identity development; and (3) communication.
\end{abstract}

\section{Keywords}

digital play; digital games; meaningful play; qualitative interviews; pediatric cancer; serious digital play

\section{Issue}

This article is part of the issue "Games and Communication-Quo Vadis?" edited by Marko Siitonen (University of Jyväskylä, Finland), Felix Reer (University of Muenster, Germany) and Teresa de la Hera (Erasmus University Rotterdam, The Netherlands).

(C) 2021 by the authors; licensee Cogitatio (Lisbon, Portugal). This article is licensed under a Creative Commons Attribution 4.0 International License (CC BY).

\section{Introduction}

In Europe alone, more than 120,000 children and 150,000 adolescents are diagnosed with cancer every year (Steliarova-Foucher et al., 2018). Thanks to treatment innovations the survival rates of young cancer patients increase substantially every year, but improved prognoses are often linked to longer treatment, including longer hospitalization periods (Long \& Marsland,
2011), and longer periods of isolation both in inpatient and outpatient care. Consequently, long-term cancer treatment is perceived as extremely challenging for young cancer patients and their families (Berríos-Rivera, Rivero-Vergne, \& Romero, 2008).

To cope with the social, emotional, and developmental challenges associated with long-term cancer treatment, play and playful activities are broadly recognized as fundamental for adolescents and children (Nijhof 
et al., 2018). However, the situation of limited contact with friends and loved ones, together with the physical limitations and psychological distress associated with the illness and the treatment, have an impact on young patients' 'playness' (Gillis, 1989). Thus, fostering play and playful interactions during long-term cancer treatment is fundamental for young patients.

Efforts in this direction are increasingly being advanced. Many hospital settings are now equipped with playroom areas for young patients and have begun to incorporate play activities as well. Yet, it is important to highlight that the benefits of these efforts are oftentimes missed by children that are immobilized or isolated for physical or medical reasons, and it is these children that are more impacted by the lack of this type of support (Gillis, 1989; Rae, Sullivan, \& Askins, 2016). Under these circumstances, digital tools offer valuable alternatives to both alleviate limitations and complement children's participation in playful activities during long-term cancer treatment (Lambert, Coad, Hicks, \& Glacken, 2014). Consequently, digital tools' social leisure value in healthcare contexts deserves special attention (Nijhof et al., 2018; Williams, Ben Birk, Petkus, \& Clark, 2019).

Although academic interest in the role of digital play for cancer patients is not new, several aspects remain under-researched. First, most previous studies have focused on exploring structured and guided play activities designed to convey health-related information (e.g., Beale, Marín-Bowling, Guthrie, \& Kato, 2006) or with therapeutic purposes such as pain relief (see Ghazisaeidi, Safdari, Goodini, Mirzaiee, \& Farzi, 2017). However, little attention has been paid to the role of unstructured free digital play during cancer treatment, and the few studies that have explored it focus on free digital play activities limited only to hospital settings organized and supervised by adults. This project, therefore, is focused on exploring the role of free (unstructured) digital play for young cancer patients during all stages of the treatment, not only during hospitalization. This article provides an answer to the following research question: What is the role of free digital play during young patients' (0-19 years) cancer treatment?

The nature of this study is exploratory as it is the first stage of a bigger research project. Thus, the aim here is to explore and identify directions for future research regarding the meaning and relevance of digital play for young cancer patients in two countries: Spain and the U.S. The relevance of this project is twofold, referring both to the societal impact and scientific possibilities: First, services and resources focused on fostering play are fundamental to support the increasing number of young cancer patients facing the challenges associated with the limitations they experience in their ability to play during all phases of the treatment; second, the increasing penetration of digital technologies and the popularization of digital games have opened new possibilities to foster the positive role of digital play in this context.

\section{Theoretical Framework}

\subsection{The Role of Play during Cancer Treatment}

For children, play is a fundamental way to develop their imagination and resourcefulness, and a way to individually test their courage, initiative, and daring (Haiat, Bar-Mor, \& Shochat, 2003). Through play, children and adolescents develop and consolidate their identities and their capacity to handle daily social interactions and events (Piage, 1967). The absence of play or an unwillingness to play is in many cases the first symptom that children show when they are not feeling well (Liptzin, as cited in Haiat et al., 2003). At the same time, play can be crucial for children undergoing long-term illnesses insofar as it can help them regain their equilibrium (Rutter, 1981). Among two of the valuable characteristics of play is that it is voluntary and it offers freedom of choice (Haiat et al., 2003) and freedom of expression (Burroughs \& Evans, 1986), freeing players from the struggles of their daily circumstances. Equally important is the sense of control that children can experience when making their own decisions during play. Finally, play can also be linked to hope: While playing, anything is possible (Hewes, 2014). For these reasons, play should not be only labelled as an entertaining activity focused on having fun, but a fundamental activity necessary for emotional balance.

Despite the relevance of play for children in general, literature exploring the play behavior of hospitalized children shows that the side effects of the illness and the circumstances of hospitalization have a disruptive effect on their play performance (Tisza, Hurwitz, \& Angoff, 1970). For these reasons, interventions focused on fostering play during hospital stays are necessary and should be available (Bolig, 2018). It is possible to distinguish between three types of play interventions in healthcare contexts: (1) therapeutic play, which is play interventions with physical or psychological therapeutic purposes; (2) medical/hospital play, which involves play activities designed to prepare the children for hospital experiences; and (3) free play, which means settings or services provided to give children opportunities to freely play (Bolig, 2018).

While therapeutic play and medical play are structured play sessions guided by an adult, free play is focused on fostering unstructured play sessions in which children have the opportunity to choose what they do. Moreover, the unpredictable nature of spontaneous free play helps children to learn to adapt to the unexpected, gaining skills related to flexibility and resilience to respond to unanticipated circumstances, which are common during cancer treatment. Therefore, through play, children can learn how to navigate difficult circumstances, reducing the anxiousness that this exploration might bring (Hewes, 2014). For these reasons, understanding the relevance and role of free and spontaneous play for young cancer patients is crucial. 


\subsection{Digital Play during Cancer Treatment}

Digital play can be seen as an important alternative to cope with the challenges associated with serious illnesses. The capacity of children undergoing cancer treatment to play might have been limited, or they might be experiencing a diminished or absence of willingness to play due to the side effects of the treatment. Furthermore, many children in cancer treatment are in situations of medical isolation or have their movements limited due to the use of specific instruments or medication. For this reason, when they look for entertainment many young patients choose activities that they can carry out from their room or bed (Lima \& Santos, 2015). In this context, it is relevant to better understand the role that technologies have in the way children play and how they use them to socialize in all settings, not only playrooms.

Moreover, it is relevant to consider the fact that children's digital and non-digital practices are not completely disconnected and that there are new ways in which they merge these two domains (Jones, Chik, \& Hafner, 2015). It is common, for example, to see young children basing their play activities on media narratives or characters (Sutton-Smith, 2008), thus engaging in mediated meaning-making practices in which what is seen on screens transforms their physical playful interactions with non-digital objects and individuals (Burnett, Merchant, Pahl, \& Rowsell, 2014). This means that it should not be assumed that digital play displaces or replaces other practices, but that it could have the potential to foster or enhance spontaneous and unstructured play in the way we see it in the daily routines of children (Huh, 2017). For this reason, it is relevant to explore youngsters' capacity to incorporate digital technologies and digital universes in their playful interactions during cancer treatment.

\subsection{Digital Play and Social Interactions}

Cancer treatment not only limits young patients' capacity to play, but also their capacity to maintain social connections. Making new friends or investing in existing bonds serves children not only to critically think about their own emotions and feelings but is also an important part of their identity development (Fitzgerald, Fitzgerald, \& Aherne, 2012). During long-term treatment, peer relations also gain paramount relevance because emotional support from friends is fundamental to cope with negative experiences (Shochet \& Smith, 2014). Despite this, young cancer patients report having difficulties keeping contact with existing social bonds during treatment (Gibson, Richarson, Hey, Horstman, \& O'Leary, 2005). Thus, fostering social interactions for young patients is vital to prevent the negative consequences linked to social isolation or loneliness. Concretely, digital games give players chances to establish social connections (Colwell, 2007; Russoniello, O’Brien, \& Parks, 2009) and are in some cases useful to alleviate the lack of social ties, becoming a useful resource to socialize and prevent feelings of loneliness (Griffiths \& Meredith, 2009).

Despite their potential, digital games have been assigned the label of antisocial (Kowert \& Kaye, 2018), opening debates in which teachers, researchers, policymakers and parents have expressed concerns and criticism about the impact of games on children and adolescents (Bryce \& Rutter, 2003). However, the old assumption that digital game players have small or deteriorated social networks (Williams, 2006), has proven to be inaccurate, as contemporary digital games offer multiple opportunities for social interaction (de Kort, Poels, \& ljsselsteijn, 2007; Kowert \& Kaye, 2018). Previous studies have shown how shared online play supports long-lasting bonds and serves to mediate in intimate conversations, which friends sometimes use to disclose sensitive or personal information or to discuss their worries (Cole \& Griffiths, 2007). Therefore, exploring the role of digital play in relation to social interactions for young cancer patients is of special relevance.

\section{Methodology}

To explore the role of digital play for young cancer patients, this study takes a qualitative approach. It is important to highlight the exploratory nature of this study, which is the first stage of a bigger research project. Thus, the aim here is to explore and identify directions for future research regarding the meaning and relevance of digital play for young cancer patients in two countries, Spain and the U.S. Concretely, 15 semi-structured interviews were conducted during the period March-September 2019. Interviews were carried out via phone calls and lasted 45 minutes on average. Two groups of informants participated in this study. First, four expert interviews were conducted, with one childlife specialist, one volunteer coordinator, and two managers of gaming organizations/foundations that collaborate closely with hospitals' pediatric oncology departments. The data gathered during these interviews was not only considered in the analysis but also used to identify relevant topics to address with the second group of participants, namely 11 Spanish parents of young cancer patients (0-17 years old). Interviews with experts were conducted in English, while interviews with parents were conducted in Spanish. The quotations included in this article from the latter set of interviews were translated from Spanish into English by the authors.

The parents participating in this study have children who were undergoing cancer treatment or had undergone such treatment in recent years. All children were between 0 and 17 years old during the cancer treatment, and the treatment was long term, i.e., at least one year. Therefore, most children had faced critical intervals of social isolation both at the hospital and at home. Parents were contacted through snowball sampling using the social network of Juegaterapia, a Spanish foundation that delivers digital game consoles for children hospi- 
talized in diverse hospitals in Spain. While recognizing the limitations of snowball sampling, this method was considered the best way to contact participants for this study given the difficulty in finding parents of young cancer patients who were actively playing digital games during treatment.

Conversations with the parents revolved around children's use of digital platforms during cancer treatment, emphasizing their motivations to play digitally, methods and patterns of use, perceived benefits and drawbacks of digital games during treatment, and impact on children's social interactions, identity development, and personal narrative.

The transcriptions of the interviews were analyzed using thematic analysis. The researchers followed the six-step process proposed by Braun and Clarke (2006). The analysis of the data was conducted through an inductive approach, paying attention to emerging themes. One of the researchers was responsible for the initial coding phase, which was supervised by the second researcher. Sub-themes and main themes were individually identified by both researchers first, which were then discussed and adjusted later by both researchers to lead to the results discussed in this article.

Research in the context of pediatric cancer treatment can trigger uncomfortable or negative feelings for the parents interviewed. Thus, bearing in mind the sensitivity of the topic, this study put an important emphasis on ethical considerations. For this reason, parents were interviewed instead of their children during this exploratory phase of the project, to identify relevant themes to discuss with the children during a later stage of this project, and thereby protecting the most vulnerable group at this stage. Furthermore, all individuals were informed before the interview about the purpose and scope of this research project, as well as the topics to be discussed during the conversation. Informed consent was obtained to participate and record the interviews, which made clear that participants could end the interview at any time and refuse to answer any questions or issues that were uncomfortable for them. Audio recordings (as well as transcripts) of all interviews are stored for the duration of the research at a secure server location of the Erasmus University Rotterdam. In this article, only the initials of the parents interviewed are used, in order to preserve their anonymity.

\section{Results}

The analysis of the data has resulted in three main themes. We have identified that in order to understand the role of digital play for young cancer patients it is important to pay attention to: (1) phases of the treatment in which digital play is relevant; (2) types of digital play young cancer patients engage with; and (3) the impact of digital play on young cancer patients. These three themes and the sub-themes linked to them are discussed in detail in the following three sub-sections.

\subsection{Three Phases of Young Patients' Cancer Treatment in Which Digital Play Is Relevant}

During the interviews, all participants agreed on the benefits of digital play for young cancer patients, recognizing its relevance to cope with the difficult experiences lived throughout the entire treatment. Although all parents were asked about the negative aspects of digital play for their children, none of them expressed major concerns in this regard. Instead, they described digital play in the context of cancer treatment as "tremendously valuable," "a great advantage," or as "a fundamental tool to change children's perception of the disease." What is most important is to note that playing digitally was perceived not only crucial during (a) inpatient care at the hospital, but also during (b) outpatient care at home and even during (c) the remission phase. Depending on the phase of the treatment, different roles of digital play were highlighted by the participants.

\subsubsection{At Hospital during Inpatient Care}

The main role of digital play during inpatient care identified in the interviews was the normalization of the hospital experience. Because children and their families suffer a drastic change in daily life routines, digital play serves as a tool that often connects patients to known or familiar activities that they used to do before the treatment. The normalization of this experience often depends on the possibility that children have to overcome physical limitations caused by both the treatment itself and by isolation periods. Many parents expressed concerns regarding the lack of opportunities that isolated hospitalized children have to use the playing facilities of the hospital or to attend ludic workshops:

He was almost always isolated, so the game had to be in the room. We had to ask to let us take in a console for him to play. He didn't have many options...he couldn't go out because there is a playroom but of course, it's for when kids are feeling well, so he was playing alone in the room. And logically what helps you the most, in that case, are digital games. (N.)

\subsubsection{At Home during Outpatient Care}

Outpatient care is another phase of cancer treatment often experienced by young patients. During periods of homestay, children are still bounded to isolation. In many cases visits are limited to family members and there are very few opportunities in which they can go outside. The majority of interviewees recognized how their children had difficulties in engaging in ludic activities, such as playing with toys, painting, doing role-play, or in general other forms of traditional games at home. Thus, digital play has also been perceived by the parents as very relevant to this phase of the treatment. 
It is important to mention that parents expressed how they would actively try to engage their children in alternative activities, such as reading a book or playing board games, in an attempt to limit contact with technology during outpatient care. In many cases, the need to limit children's time with technology seemed to emerge from what interviewees expressed as a fear of addiction or dependence. Besides this, parents also recognized being much more flexible with digital play during inpatient care than at home:

We have to adapt. In the hospital, we are quite flexible. At home we try to not be too dependent on them [digital technologies] because in the end, of course, there are many hours in the hospital, many days and she needs a lot of things to do. At home we set rules, [and] we let her play a maximum number of hours per day. (N.)

\subsubsection{During Remission}

During remission, children begin to resume daily activities and other routines, while still attending regular check-ups. Consequently, the relevance of digital play during remission is closely related to their possibilities of integrating back into daily life. The majority of interviewees explained how digital games and other digital technologies helped children connect with others once they were back in school. Recovering friendships and re-establishing the social circle fragmented due to the illness were important concerns expressed by parents regarding their children's reintegration. The role of digital games in this regard cannot be taken lightly, especially when considering that playing digitally is a widely extended practice among young children today. In fact, as L. mentioned, digital games were for her daughter, "a way of engaging back when facing school. When my daughter returned after a year of not going to school, all her friends had grown up...and the way she recovered those friendships was by bringing popular games to school" (L.).

Integrating back into daily life can be a challenging process for children who have been absent for months or even years. In the case of Y., a child who spent more than 5 years in the hospital after being diagnosed when he was only a few months old, digital games were his single common-ground topic with other children. His mother explained how, while conversation about amusement parks or the First Communion "sounded like Chinese to Y.," he could use digital technologies to build relationships and bring friends home to play, have fun, and connect.

\subsection{Types of Digital Play during Young Patients' Cancer Treatment}

Previously we have established the value of digital games for children and their families at different phases of treat- ment, understanding the multiple relevant roles that these technologies can play in each phase. In this subsection, we turn to discuss in more detail the different genres, platforms, and ways in which children combine digital games with both digital and non-digital tools during cancer treatment.

\subsubsection{Playing Digital Games}

The genres chosen by children were often-though not always-linked to differences in their age. Concretely, younger children (0-4), who often discovered digital games as a consequence of their hospitalization, have preferences for logic games, didactic games, and simple skill games. This preference was perceived by parents who explained how these games were helpful for their children to develop abilities appropriate for their age, which might have been difficult to acquire during longterm cancer treatment. The case of Y., who was hospitalized at only 6 months old, illustrates this point. After the first two years at the hospital, Y. started using a tablet to develop multiple skills, from completing memory challenges and putting puzzles together, to following recipes in cooking games or familiarizing with daily life concepts.

A similar experience was shared by S., mother of E., a two-year-old girl at the time of the diagnosis, who described her daughter's preferences for games that allowed her to accomplish small goals. Like Y., E. also discovered digital games after hospitalization and expressed great motivation for using digital tools to relate with the outside world, for example, by learning the names of animals through different skill games.

Participants also described sports and races games as preferred by older children. The social character of these games has been crucial for older children to develop a sense of competition. Lastly, platform games were perhaps the most mentioned genre, played across different devices and treatment phases. Because platform games are primarily about overcoming obstacles to advance in the game's levels, many parents described them as a way in which children relate to their illness. For example, the Mario Bros. series was mentioned by the majority of the parents as one of the favorite games played both during inpatient and outpatient care, and that sparked a fighting mindset in their children that helped them cope with difficult situations:

I think he liked Mario Bros. because it's a character who didn't stop, who had to pass tests and keep going, and I think that's what he had to do at that time too: overcoming. And of course, he liked it a lot; it's a very active game, about jumping and passing tests, and he loved it. (P.)

\subsubsection{Playfully Interacting with Other Technologies}

During interviews, it also became apparent that parents associated digital play not only with playing digital 
games but also playfully interacting with different digital devices. Parents explained how their children engaged in playful attitudes while for example using a camera or cellphones, by for instance taking pictures of multiple funny faces or taking pictures upside down. J., for example, explained how her two-year-old daughter used to playfully engage with her tablet by recording videos of herself. This speaks to children's ability to navigate digital tools intuitively and make them part of their overall playing experience during treatment.

Furthermore, many parents described how their children used YouTube to search and learn how to play a digital game, how to move forward in a game, or simply to watch other children play the same or similar games:

My son watches videos of how to use certain game tricks to play, or if he is somewhere and does not know how to go out then he uses my cellphone, [searching for] "how do I get out of here?" or "how do I pick up this or that tool?" (C.)

Comparable episodes were narrated by parents who frequently highlighted the ease with which their children would handle a tablet or cellphone to look for videos and content, not only to learn how to play but also to discover new games.

\subsubsection{Overlap between Digital and Non-Digital Play}

Interacting with different digital technologies is not the only way children enrich their playing experience; according to the interviewees, children have also combined digital and non-digital forms of play on different occasions during treatment. The overlapping of digital and non-digital practices was commonly described by parents, who perceived it as a way of experiencing the outside world through digital technologies after children were socially isolated due to treatment. As S. explained, her daughter $\mathrm{E}$. used the tablet to recover playing experiences that used to take place in the outside world from which she was isolated after being diagnosed:

Instead of saying "I want to go to the park" or "I want to go to the pool," it was more like "I'm going through this." Whatever she wanted to do at a certain moment, she would do it through the phone or the tablet. (S.)

Other parents describe how their children would engage in role-play following a digital game scenario or imitating a character. As one mother explained, even though sometimes her son does not have access to Fortnite or Pokémon, he often recreates game scenes or embodies the main characters. Parents explain how playing to match the qualities of certain digital game characters has helped young cancer patients feel more secure during critical phases of treatment and medical procedures. This is the case for many children who, guided by their parents, understood difficult experiences as embedded in playing where they were the main character. This is the case for P.'s son who embodied the qualities of his favorite video game character to face a CT scan:

He was a lot like Mario, so he would say to me "look, I'll do it like Mario, if he overcomes stuff and today is my turn, l'll do it the same as Mario." So, indeed, he strongly identified with the character that in this case was Mario. It was helpful, it gave him motivation. (P.)

This process, in which children combine digital and nondigital games, not only enriches their playing practices, but also significantly impacts their experiences during long-term cancer treatment. In the following section, we discuss such impact in more detail.

\subsection{Types of Impacts of Digital Play on Young Cancer Patients}

During the interviews, the impact of digital play on young cancer patients was also discussed. As described by many participants, an important consequence of long-term cancer treatment seems to be the "loss of childhood." Digital play can be tremendously valuable in dealing with such a process. In general, three types of impacts were identified and thus discussed hereafter: (a) social interactions; (b) identity development; and (c) communication.

\subsubsection{Social Interaction}

Due to the illness, many of the children's social relations are weakened. While they leave behind family and friends, they enter an environment where establishing new relations can be challenging, especially when they are isolated. In this regard, most participants recognized that digital games can be crucial for restoring children's social circle in concrete ways: making new friends, and in some cases, keeping contact with loved ones left behind. As explained by the co-founder of Fully Loaded Electronics (a company that provides gaming equipment for hospitals in the U.S.), digital games can act as a starting point that children use to build meaningful relations at the hospital, providing them with a bonding experience that is difficult to develop in their circumstances (personal communication). In fact, many parents described how through play, their children could overcome the shyness and discomfort of meeting new friends, as they saw it as a sort of platform that facilitated friendship.

Digital play can also be extremely important to maintain social connections. Many parents identified the relevance of digital games to keep up with other children's experiences-a crucial aspect in strengthening social connections outside of the hospital as well:

Digital games and being up to date are evidently important because all his classmates are into it. It's 
great that he's not left behind in that, because it gives him the opportunity to be able to connect with them immediately; to be able to play whatever they want, the latest digital game, because they know it and know how it works because they have been playing it. In that, they are exactly the same. (V.)

It is important to highlight that some parents perceived an advantage of games over other forms of connection through technology, such as video calls or cellphone calls. For example, some parents mentioned that although sometimes their children did not feel like calling family or friends, they did feel more comfortable maintaining these social connections through online play. Some parents even recognized that their children preferred to cut off contact with their school friends, because they felt ashamed of their condition or were afraid of being pointed out by others; under these circumstances, online play was considered an optimal resource.

\subsubsection{Identity Development}

Free and spontaneous play fulfils an important role in the development of the child's identity during treatment, especially when confronting the sense of childhood loss. Many aspects were identified related to this type of impact: how children develop certain traits such as resilience and autonomy, how they discover likes and preferences through digital games such as sports or vocations, or how they adopt and grow qualities from gaming characters to face difficult situations. All these processes evidently play a role in the development of their identity, which, according to interviewees, manifest in specific situations, even after the treatment is over. As M. J. said, "for my son, the games have been everything, Y. is what he is thanks to the games."

An overarching aspect of the impact that digital play has on children's identity development is the value of digital games in helping them to identify as more than sick children. Playing digitally offers children an opportunity to "broaden who they are, from 'just a kid with an illness' to 'a kid who's playing digital games and who also by the way, you know, has an illness,"' in the words of Fully Loaded Electronics' co-founder (personal communication). This broadening of their identity is also related to the opportunities that children have to preserve and perform their childhood, even when facing a serious illness. For example, one participant explained how there were times when her son seemed to forget about being a kid with an illness and instead turned all his attention to being a kid playing digital games: after receiving chemotherapy, he could be immersed in the playing narrative in such a way that secondary effects of the treatment were even imperceptible for him. In his mother's own words, "in those moments, there is no disease, there is nothing; it is just a kid playing" (V.).

J.'s account also speaks to the agency that children recover as a consequence of broadening their identity during the illness: In free and spontaneous play they decide where to go, what to do, when, with whom, and so forth. Such decisions, limited in the physical world, become possible digitally where they have control over the gaming experience. The relevance of recovering agency has also been recognized by Marty, Digital Gaming Coordinator at Texas Children's Hospital, who explained that during the illness:

Doctors, nurses, everybody else in the hospital is giving them things they have to do, and kind of telling them things, so just being open to whatever they want to do, giving them the reins and the control of the session...can definitely help them to kind of regain a lot of that control, especially for long-term stays. (Marty)

Additionally, an important consequence of the impact that digital play has on young cancer patients is the way they remember their treatment experience: Broadening their identity and enabling agency seemed to aid the construction of a personal narrative in which cancer treatment can even become a fun and enjoyable process. In fact, many parents accounted for the positive way in which children remember their illness.

\subsubsection{Communication}

Lastly, digital play was also found to have an impact on the ways in which children communicate with others. In this case, we explored the capacity or willingness of children to communicate about their process and, also, the ability of parents to address both treatmentrelated issues as well as other topics with their children. Particularly, playing experiences seemed to be perceived by the participants as a resource to overcome various communication barriers faced during treatment. One such barrier is the lack of conversation topics, a clear consequence of long and monotonous days at the hospital or at home. In this regard, Shikha, manager of the Program Impact at the Starlight Children Foundation, accounts for several occasions when shared playing experiences between children and their parents could help overcome this difficulty. According to her, when "you're pulling teeth trying to make a conversation happen," sharing a game can be a common experience to connect on and build bridges of communication between parents and children who are living the disease in two radically different ways. Such differences can result in difficulties to empathize with the children's experience:

You're running out of conversations, there's a lot of silence. Then you pick up there, you start a conversation because these are conversations that lead you to avoid what is happening and then you use it...is something that I know he is interested in and that takes us out of the silence...simply talk to him about something else, which is much more fun than treatment. (C.) 
Another communication challenge experienced by parents is the difficulty of knowing how their children feel during treatment. Playing was perceived by some parents as a way of navigating better sensitive conversations about the illness. For example, P. remembered "initiating deeper conversations through the games" which has helped her to engage her son in a sort of "therapy for him to express his feelings." Similarly, digital games have sometimes been useful for some young cancer patients to express with more ease how they are feeling throughout the treatment, by using examples such as "I feel sad like when Pikachu lost $x$ match" or similar.

Conversely, the games have also allowed parents to communicate better about the consequences or procedures associated with the disease to their children, which is one of the most complicated and important challenges during the process. Concretely, parents acknowledged using digital game examples to encourage their children and explain some of the processes. For instance, seizing the child's ability to identify with the characters, one of the mothers said that at times she has used metaphors:

We have said 'you're going to take Hulk's medicine, you'll see how strong you're going to be, you're going to heal.' That has always been present. Or in many situations, it's like 'Pikachu has faced I don't know who in a mega-challenge, now you have to do it yourself.' We have used this more than once. (M.)

In this case, $M$. sees the value of using this kind of metaphor insofar as it is a language that is easy for her son to interpret and to feel comfortable with when talking about complicated procedures or concepts that are difficult for young cancer patients to grasp.

\section{Discussion and Conclusions}

This exploratory study was designed to better understand the role of digital play for young cancer patients. The results of analyzing the data collected through 15 qualitative interviews show that digital play becomes a valuable activity for young cancer patients beyond (1) inpatient care. Accordingly, our study shows that patients can benefit tremendously from digital play during (2) outpatient care and (3) remission too. Considering that the role of digital games has been overlooked in cancer treatment outside of hospital settings, we propose to advance studies in this direction, not only aiming to better understand the relevance of digital play in all three stages of treatment but also to understand how its presence during one phase has an impact on its role during other phases.

We were also able to identify three types of digital play patients engage with: (1) playing with digital games; (2) playfully interacting with digital technologies; and (3) the overlap between digital and non-digital play activities. The different ways in which young patients engage in spontaneous free digital play suggest the need to broaden our conventional understanding of digital play, which is currently limited to digital games, to include other forms of interaction with technologies. Therefore, we also recommend future research to pay attention to young cancer patients' motivations to play digitally, their preferred methods, patterns of use, perceived benefits and limitations, and impact on children's development, among other things. These are timely and relevant issues, not only considering the rapid penetration of digital play nowadays, but also bearing in mind how this knowledge is indispensable to ensure the efficient implementation of this type of service and technology during all phases of the treatment.

Finally, the results also show that digital play has an impact on at least three aspects of young patients' lives: (1) social interactions; (2) identity development; and (3) communication. These results are in line with previous research in the field of game studies, supporting the idea that online games are nowadays considered exceptional social spaces affording communication and fostering interaction even among socially anxious or introverted individuals (Kowert \& Kaye, 2018; Ramirez \& Zhang, 2007). For young cancer patients, these affordances could be key to help normalize the overall experience of cancer treatment and isolation as our results suggest. Thus, the relevance of the social interactions triggered by digital games nowadays cannot be taken lightly (de Kort et al., 2007). The results of this study therefore open up clear new avenues for continuing the exploration of this phenomenon, which will be explored in future steps of the research project of which this study is part.

We acknowledge that the number of interviews $(n=15)$ conducted for this study is limited and the results are mainly connected to the patients participating in the programs carried out by the NGO who facilitated the sampling process. This only provides a limited understanding of this phenomenon; however, we would like to highlight the exploratory nature of this study, which is the first stage of a bigger research project. Thus, the aim here was to identify directions for future research regarding the meaning and relevance of digital play for young cancer patients. Thanks to this exploratory study we have understood the relevance of studying this phenomenon in and out of the hospital during three different phases of the treatment, and also the need to understand the connection of the role of digital play during these three phases, which will serve to structure future phases of this project.

A decision was made not to interview children at this exploratory stage of the process, as the sensitivity of the subject first requires a thorough understanding of the topic to better approach children whose lives have been greatly affected by cancer treatment. We acknowledge that this is a limitation of this study, as conducting interviews directly with young cancer patients would result in more meaningful data, but this can be contemplated for the following stages of the research project. 


\section{Acknowledgments}

We would like to thank all the parents who agreed to participate in this study and shared their valuable time to make it happen. We also would like to thank Juegaterapia for facilitating access to the participants to this study. Finally, we would like to thank the representatives of Starlight Children's Foundation, Fully Loaded Electronics, and Texas Children's Hospital for contributing to this study by providing their professional point of view.

\section{Conflict of Interests}

The authors declare no conflict of interests.

\section{References}

Beale, I. L., Marín-Bowling, V. M., Guthrie, N., \& Kato, P. M. (2006). Young cancer patients' perceptions of a video game used to promote self care. The International Electronic Journal of Health Education, 9, 202-212.

Berríos-Rivera, R., Rivero-Vergne, A., \& Romero, I. (2008). The pediatric cancer hospitalization experience: Reality co-constructed. Journal of Pediatric Oncology Nursing, 25(6), 340-356. https://doi.org/10.1177/ 1043454208323618

Bolig, R. (2018). Play in hospital settings. In T. D. Yawkey \& A. D. Pellegrini (Eds.), Child's play: Developmental and applied (pp. 323-346). London: Routledge. https://doi.org/10.4324/9781315099071

Braun, V., \& Clarke, V. (2006). Using thematic analysis in psychology. Qualitative Research in Psychology, 3(2), 77-101. https://doi.org/10.1191/ 1478088706qp063oa

Bryce, J., \& Rutter, J. (2003). The gendering of computer gaming: Experience and space. In S. Fleming \& I. Jones (Eds.), Leisure cultures: Investigations in sport, media and technology (pp. 3-22). Eastbourne: Leisure Studies Association.

Burnett, C., Merchant, G., Pahl, K., \& Rowsell, J. (2014). The (im)materiality of literacy: The significance of subjectivity to new literacies research. Discourse: Studies in the Cultural Politics of Education, 35(1), 90-103. https://doi.org/10.1080/01596306. 2012.739469

Burroughs, S., \& Evans, R. (1986). Play, language, and socialisation: Perspectives on adult roles. New York, NY: Routledge.

Cole, H., \& Griffiths, M. D. (2007). Social interactions in massively multiplayer online role-playing gamers. CyberPsychology \& Behavior, 10(4), 575-583. https://doi.org/10.1089/cpb.2007.9988

Colwell, J. (2007). Needs met through computer game play among adolescents. Personality and Individual Differences, 43(8), 2072-2082. https://doi.org/ 10.1016/J.PAID.2007.06.021

de Kort, Y. A. W., Poels, K., \& Ijsselsteijn, W. A. (2007).
Digital games as social presence technology: Development of the social presence in gaming questionnaire (SPGQ). In L. Moreno (Ed.), Proceedings of the 10th Annual International Workshop on Presence (pp. 195-203). Barcelona: Starlab. Retrieved from https:// www.researchgate.net/publication/228091680

Fitzgerald, A., Fitzgerald, N., \& Aherne, C. (2012). Do peers matter? A review of peer and/or friends' influence on physical activity among American adolescents. Journal of Adolescence, 35(4), 941-958. https://doi.org/10.1016/j.adolescence.2012.01.002

Ghazisaeidi, M., Safdari, R., Goodini, A., Mirzaiee, M., \& Farzi, J. (2017). Digital games as an effective approach for cancer management: Opportunities and challenges. Journal of Education and Health Promotion, 6, 30. https://doi.org/10.4103/jehp.jehp_146_14

Gibson, F., Richarson, A., Hey, S., Horstman, M., \& O'Leary, C. (2005). Listening to children and young people with cancer. London: Institute of Child Health.

Gillis, A. J. (1989). The effect of play on immobilized children in hospital. International Journal of Nursing Studies, 26(3), 261-269. https://doi.org/ 10.1016/0020-7489(89)90007-2

Griffiths, M. D., \& Meredith, A. (2009). Digital game addiction and its treatment. Journal of Contemporary Psychotherapy, 39(4), 247-253. https://doi.org/ 10.1007/s10879-009-9118-4

Haiat, H., Bar-Mor, G., \& Shochat, M. (2003). The world of the child: A world of play even in the hospital. Journal of Pediatric Nursing, 18(3), 209-214. https://doi.org/ 10.1053/jpdn.2003.28

Hewes, J. (2014). Seeking balance in motion: The role of spontaneous free play in promoting social and emotional health in early childhood care and education. Children, 1(3), 280-301. https://doi.org/ 10.3390/children 1030280

Huh, Y. J. (2017). Uncovering young children's transformative digital game play through the exploration of three-year-old children's cases. Contemporary Issues in Early Childhood, 18(2), 179-195. https://doi.org/ 10.1177/1463949117714080

Jones, R. H., Chik, A., \& Hafner, C. A. (2015). Discourse and digital practices: Doing discourse analysis in the digital age. New York, NY: Routledge.

Kowert, R., \& Kaye, L. K. (2018). Video games are not socially isolating. In C. Ferguson (Ed.), Video game influences on aggression, cognition, and attention (pp. 185-195). Cham: Springer. https://doi.org/ 10.1007/978-3-319-95495-0_15

Lambert, V., Coad, J., Hicks, P., \& Glacken, M. (2014). Social spaces for young children in hospital. Child: Care, Health and Development, 40(2), 195-204. https://doi.org/10.1111/cch.12016

Lima, K. Y. N., \& Santos, V. E. P. (2015). Play as a care strategy for children with cancer. Revista Gaúcha de Enfermagem, 36(2), 76-81. https://doi.org/10.1590/ 1983-1447.2015.02.51514

Long, K. A., \& Marsland, A. L. (2011). Family adjustment 
to childhood cancer: A systematic review. Clinical Child and Family Psychology Review, 14(1), 57-88. https://doi.org/10.1007/s10567-010-0082-z

Nijhof, S. L., Vinkers, C. H., van Geelen, S. M., Duijff, S. N., Achterberg, E. J. J. M., van der Net, J., ... Lesscher, H. M. B. (2018). Healthy play, better coping: The importance of play for the development of children in health and disease. Neuroscience and Biobehavioral Reviews, 95, 421-429. https://doi.org/10.1016/ j.neubiorev.2018.09.024

Piage, G. (1967). The philosophy of the child. Tel Aviv, IS: Hipoalim.

Rae, W. A., Sullivan, J. R., \& Askins, M. A. (2016). Play interventions for hospitalized children. In L. A. Reddy, T. M. Files-Hall, \& C. E. Schaefer (Eds.), Empirically based play interventions for children (2nd ed., pp. 115-133). Washington, DC: American Psychological Association. https://doi.org/10.1037/14730-007

Ramirez, A., Jr., \& Zhang, S. (2007). When online meets offline: The effect of modality switching on relational communication. Communication Monographs, 74(3), 287-310. https://doi.org/10.1080/ 03637750701543493

Russoniello, C. V., O'Brien, K., \& Parks, J. M. (2009). The effectiveness of casual video games in improving mood and decreasing stress. Journal of Cyber Therapy and Rehabilitation, 2(1), 53-66.

Rutter, M. (1981). Maternal deprivation reassessed (2nd ed.). Harmondsworth: Penguin Books.

Shochet, I. M., \& Smith, C. L. (2014). A prospective study investigating the links among classroom environment, school connectedness, and depressive symptoms in adolescents. Psychology in the Schools, 51(5), 480-492. https://doi.org/10.1002/pits.21759

Steliarova-Foucher, E., Fidler, M. M., Colombet, M., Lacour, B., Kaatsch, P., Piñeros, M., . . . Dolya, A. (2018). Changing geographical patterns and trends in cancer incidence in children and adolescents in Europe, 1991-2010 (automated childhood cancer information system): A population-based study. The Lancet Oncology, 19(9), 1159-1169. https://doi.org/10.1016/S1470-2045(18)30423-6

Sutton-Smith, B. (2008). Play theory: A personal journey and new thoughts. American Journal of Play, 1(1), 80-123.

Tisza, V. B., Hurwitz, I., \& Angoff, K. (1970). The use of play program by hospitalized children. Journal of the American Academy of Child Psychiatry, 9(3), 515-531. https://doi.org/10.1016/S0002-7138(09)61856-2

Williams, D. (2006). Groups and goblins: The social and civic impact of an online game. Journal of Broadcasting \& Electronic Media, 50(4), 651-670. https://doi. org/10.1207/s15506878jobem5004_5

Williams, N. A., Ben Birk, A., Petkus, J. M., \& Clark, H. (2019). Importance of play for young children facing illness and hospitalization: Rationale, opportunities, and a case study illustration. Early Child Development and Care, 128(1), 1-10. https://doi.org/10.1080/ 03004430.2019.1601088

\section{About the Authors}

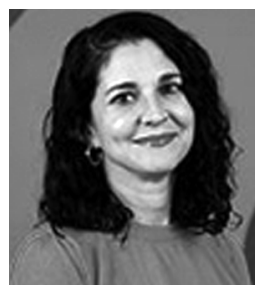

Teresa de la Hera is Assistant Professor in Persuasive Gaming at Erasmus University Rotterdam, in the Netherlands, where she is member of the Gaming Matters Research Cluster. Her expertise is in the study of the use of games and play to positively change players' attitudes and behaviors. She is the Author of the book Digital Gaming and the Advertising Landscape (2019) and the main Editor of the edited volume Persuasive Gaming in Context (2021), both published by Amsterdam University Press.

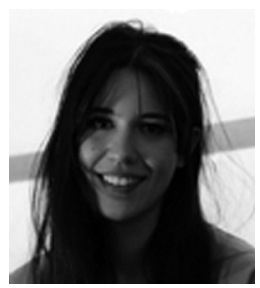

Camila Sarria Sanz is a Communication Designer and holds a MA degree in media studies from the Department of Media and Communication at Erasmus University Rotterdam, the Netherlands. She currently runs a social enterprise in Colombia, which specializes in training change-makers using social entrepreneurship and participatory design tools to develop high-impact projects. In 2017 she started her academic career and since then she has worked on different research projects. Her research interests include indigenous media practices, forced migration, citizens' media, and design thinking methodologies. 